\title{
MEMÓRIAS DO LADO DIVERTIDO DA ESCOLA PRIMÁRIA PORTUGUESA \\ DOI: http://dx.doi.org/10.1590/2236-3459/51688
}

\author{
Maria Manuela Pereira Figueiredo Rodrigues \\ Universidade de Lisboa, Portugal.
}

\begin{abstract}
Resumo
Este texto, cuja essência foi apresentada no $10^{\circ}$ congresso luso-brasileiro de História da Educação, visa a realçar, como objeto de pesquisa histórica, o lado lúdico da escola, em particular nos tempos de recreio, no espaço temporal do intervalo das lições. Os jogos e brincadeiras infantis têm o seu lugar no universo escolar e, como tal, são elementos que contribuem para a construção de uma memória da escola primária. A cultura escolar também é feita da materialidade desses jogos e brincadeiras, da diversão que se vive nos recreios das escolas. Para a realização deste trabalho utilizaram-se fontes orais, fontes manuscritas e impressas, para além de bibliografia que versa, de algum modo, acerca desta temática.

Palavras-chave: escola primária, jogos, brinquedos, espaços de recreio, cultura escolar.
\end{abstract}

\section{MEMORIES OF FUN SIDE PRIMARY SCHOOL PORTUGUESE}

\section{Abstract}

This article, whose essence was presented at the $10^{\circ}$ Portuguese-Brazilian History of Education congress, aims to enhance, as an object of historical research, the playful side of school, particularly the playtime period, between the break of lessons. Games and children's games have their place in the school environment and, as such, are elements that contribute to the construction of a elementary school memory. The school culture is also made of materiality of these games and activities, by the fun that is lived at the schoolyards. To accomplish this work was used oral sources, manuscript and printed sources, plus the bibliography which is related somehow to this theme

Key-words: elementary school, games, toys, playground, school culture.

\section{RECUERDOS DE LADO DIVERTIDO DE LA ESCUELA PRIMARIA PORTUGUESA}

\section{Resumen}

Este texto, que es la esencia de lo que se ha presentado en el $10^{\circ}$ congreso Luso-brasileño de Historia de la Educación, tiene por objeto poner de relieve, como objeto de investigación histórica, el lado más divertido de la escuela, en particular en tiempos de recreación, en espacio temporal de las enseñanzas. Juegos y juegos de los niños tienen su lugar en el universo escolar y, como 
tal, son elementos que contribuyen a la construcción de una memoria de la escuela. La cultura escolar está hecho también de la importancia de estos juegos, la diversión que vive en el patio de recreo. A los efectos del presente estudio se han utilizado fuentes orales, las fuentes manuscritas e impresas, además de literatura que se ocupa, de alguna forma, este tema.

Palabras-clave: escuela primaria, juegos, juguetes, espacios de recreación, cultura escolar.

\section{SOUVENIRS DU CÔTE LUDIQUE DE L’ÉCOLE PRIMAIRE PORTUGAISE}

\section{Résumé}

Ce texte, dont l'essence a été présenté au $10^{\mathrm{e}}$ congrès de Luso-Brazilian Histoire de l'Éducation, vise à mettre en évidence, comme un objet de la recherche historique, le côté ludique de l'école, en particulier dans les moments de loisirs, en espace temporel de leçons. Jeux et jeux d'enfants ont leur place dans l'environnement de l'école et, en tant que tels, sont des éléments qui contribuent à la construction d'une mémoire de l'école primaire. La culture scolaire est également faite de l'importance de ces jeux, le plaisir qui vit dans des terrains de jeux. Pour les fins de cette étude, on a utilisé sources orales, sources manuscrites et imprimées, en plus de la littérature qui traite, d'une certaine manière, ce thème.

Mots-clé: école élémentaire, jeux, jouets, espaces de récréation, culture scolaire. 


\section{As lembranças do passado}

$\mathrm{N}$ a génese do pensamento, da descoberta de si mesmo, da possibilidade de experimentar, de criar e de transformar, encontramos o jogo, pelo que as brincadeiras são o meio que a criança usa para contactar com o mundo: "Chez le petit enfant, jouer est manifestement le pur accomplisement de la vie" (Fink, 1966, p. 9). Assim, no seu brincar, a criança constrói e reconstrói simbolicamente a sua realidade. Ao brincar, a criança acaba por se deixar impregnar e penetrar pela atividade e pelo objeto usado, pelo que as atividades aparentemente sem importância podem ter um significado especial para os que as vivenciam. E mais importância assumem quando se recorre à memória dos mais velhos e nas emoções que transbordam no tom dos seus discursos se nota que foram marcantes os momentos lúdicos vividos na escola:

As brincadeiras eram no intervalo: andávamos a correr atrás uns dos outros, era aquela maluquice. Brincadeiras sem nexo. [...] Eu jogava à bola, cá fora, junto à minha residência, no lado da praia (não havia muralha), era praia. Aí é que a gente jogava à bola. Uma bola de trapo. $\mathrm{Na}$ escola não havia bola. Nesse tempo não havia bolas de borracha. [...] Os pais não podiam comprar bolas. Não havia bolas à venda. [...] Havia a praia... e nós vínhamos cá para a praia também brincar. [- A hora do intervalo?!] À hora do intervalo. (JBT, 2013) ${ }^{1}$

A sala cheia de rapazes e raparigas. Vinha a hora do recreio: nós todos descíamos as escadas e íamos lá para baixo, as raparigas para um lado e os rapazes para outro." [-No intervalo, que brincadeiras faziam?] Escondidas, rodas, os quatro-cantinhos; e os moços era fazer covinhas na calçada para jogar ao bugalho, e nós também jogávamos às pedrinhas, às cinco pedrinhas, e as brincadeiras de bonecas, e essas coisas todas. Nós fazíamos as bonecas e púnhamos a lã a fazer o cabelo e fazíamos os olhinhos com [...] Fazíamos imensas coisas. Não havia nada do que há agora. ${ }^{2}$ (ECM, 2013)

No entanto, importa não descurar na análise do discurso destes entrevistados a possibilidade de certo distanciamento do real, porque "o memorável é aquilo que se pode sonhar a respeito do lugar" (Certeau, 2003, p. 190). A sensação de que o que foi vivido não tem comparação possível com o que fazem as gerações actuais, está bem expressa na frase não havia nada do que há agora. É a saudade de tempos idos em que, como diz Michel de Certeau, "a lembrança é somente um príncipe encantado de passagem, que desperta, um momento, a Bela-Adormecida-no-Bosque de nossas histórias sem palavras" (2003, p. 189).

Para complementar a informação recolhida nestes dois relatos e que pode dar uma panorâmica aproximada do que seriam as atividades recreativas das crianças na escola durante as primeiras décadas do século 20, encontrou-se um estudo feito sobre a atividade lúdica na localidade de onde eram naturais estes entrevistados, do qual interessa particularmente o seguinte excerto:

\footnotetext{
${ }^{1}$ A escola a que faz referência é a Conde de Ferreira e fica junto ao rio Tejo. O parêntesis reto refere-se à minha intervenção no diálogo.

2 Tal como no depoimento anterior, o conteúdo do parêntesis reto refere-se à minha intervenção. A escola referida é a do Centro Escolar e Eleitoral Republicano Estevão de Vasconcelos. Convém salientar que a coeducação só foi introduzida em 1919.

Hist. Educ. [Online] Porto Alegre

v. 19

ก. 47

Set./dez., 2015

p. $213-227$
} 
Da recolha de narrativas de vida que tive ocasião de fazer e que constituem memórias individuais e colectivas da nossa sociedade, pode constatar-se que algumas brincadeiras como a apanhada, as mães e os pais, as compras, o pé-coxinho ou os jogos da falua, do mata, da cabracega, da sardinha, do lencinho, das escondidas, do macaquinho do chinês ou até as rodas eram praticadas na escola só por rapazes ou só por raparigas, porque não existiam, ao tempo, escolas mistas, mas eram praticadas pelos dois géneros em simultâneo, em situações de grupo de brincadeira. Já o pião, o berlinde, os polícias e ladrões, o eixo, a raspa, a rolha, o futebol (na maioria dos casos jogado com bola de trapos e pés descalços), eram jogos masculinos; as chinchadas, os 'assaltos', as brincadeiras com carros e a sua construção, as brincadeiras com arcos e com cavalos de pau ou de papel, eram tipicamente masculinas, servindo para afirmar a masculinidade de quem as praticava. Fazer e brincar com bonecas, aos jantarinhos, às cinco pedrinhas, às cabeleireiras, às modistas, à macaca, à corda, eram actividades femininas. Ao longo do tempo as brincadeiras predominantemente ou exclusivamente femininas derivam com muita frequência dos materiais adquiridos via contos de fadas e histórias. (Lavado, 2004, p. 194)

Também um dos seus entrevistados, do gênero feminino, nascido em 1909, relativamente a brincadeiras, dizia: "Brincávamos muito na escola e naquela altura havia rapazes e raparigas" (Lavado, 2004, p. 330), "a caminho da escola era brincadeiras de raparigas [...] ríamos, brincávamos, passeávamos, trocávamos dichotes umas com as outras" (p. 334). Relativamente ao tipo de brinquedos que tinham, explicava que eram a mãe e as irmãs mais velhas que Ihe faziam as bonecas de trapo, sendo os cabelos feitos com corda desfiada (p. 338).

Para alargar o espaço das memórias a informantes de outras zonas do país, selecionaram-se alguns excertos do livro coordenado por Sara Marques Pereira (2002), que é uma recolha de cerca de setenta testemunhos de entre escritores, jornalistas, professores, médicos, atores, militares, religiosos, músicos, políticos, empresários, realizadores, que aqui se reproduz:

António Augusto Simões Rodrigues: "Tinha a escola dois recreios, um maior ao nível da pequena rua que dá acesso ao pátio monástico e outro mais pequeno, situado em plano superior, à mesma altura das salas de aula.. Na parte inferior do edifício existia uma porta que dava acesso a um túnel longo e escuro, que fazia os encantos da pequenada. Era o mistério, eram as histórias cheias de fantasia que inventávamos entre nós e que exprimiam o espírito sonhador e criativo das crianças" (Idem, p. 30). "Nos recreios, os jogos variavam conforme a época. O pião teve o seu tempo, tal como a malha ou as corridas de estafeta, o arco, a corda para jogos de tracção e outros de que já não me recordo. O futebol, jogado com uma bola de pano, era apesar de tudo o que mais me entusiasmava." (Pereira, 2002, p. 31)

A. H. de Oliveira Marques: Eu na escola primária era back, defesa, no futebol como hoje se diz. [...]. Jogávamos também ao anel, que ainda se joga hoje. Depois havia a Falua: Que linda falua que lá vem, lá vem; é uma falua que vem de Belém, passará não passará.., depois fazíamos bicha, cada qual puxava para o seu lado e a que partia era a que perdia, e por aí adiante. (Pereira, 2002, p. 47) 
Vítor Manuel Trindade: "Os recreios com o Gaudêncio (o Pé de Chaparro) e o Joaquim (o Fininho), formando o trio invencível na luta de castelos contra os do Farrobo e nos jogos de pião, berlinde e futebol [...], os recreios, dizia, eram a melhor coisa." (Pereira, 2002, p. 239)

\section{Das brincadeiras aos brinquedos}

Brincar para a criança não tem o mesmo significado que tem para o adulto. Para ela, brincar não significa ficar sem fazer nada, pelo contrário; esse é o seu trabalho, pelo qual desenvolve potencialidades, descobre limites e papéis sociais, experimenta novas habilidades, forma um conceito de si, em suma, aprende a viver. Do mesmo modo que se empenha para aprender a falar, a andar, a comer, a criança envolve-se nas suas atividades de brincar. De acordo com Gilles Brougère (1998), brincar não é uma dinâmica interna do indivíduo, mas uma atividade dotada de uma significação social precisa que requer aprendizagem. Conforme cresce, as atividades de brincar, por exemplo de faz de conta ou de jogar às escondidas, são gradualmente substituídas por outras, à medida que os interesses são canalizados para novos tipos de jogos.

Se nos detivermos a observar as crianças brincando, reparamos no ar compenetrado com que assumem os papéis, incorporando-os de corpo e alma. A forma como lidam com as regras estipuladas para esses jogos, que normalmente são rígidas, acaba até por levar as crianças ao cansaço, ao ponto de serem capazes de enfrentar o perigo e o sofrimento (Freinet, 1974). A identificação momentânea com a personagem chega a ser de tal modo absorvente nos primeiros anos que nada daquilo é mero divertimento, é mesmo coisa séria. As crianças detestam ser interrompidas nas suas brincadeiras e não admitem zombarias, pelo que procuram ignorar a interrupção, às vezes ficam irritadas ou até mesmo agressivas. A seriedade do jogo obriga a um afastamento do mundo real por parte da criança, para se tornar na personagem em questão, dando ênfase à simulação e ao faz de conta. $O$ jogo constitui, assim, um mundo à parte, outro mundo, distante do mundo dos adultos, em que a criança se sente mais próxima do essencial e do autêntico.

Assim que a personalidade das crianças se afirma, e antes de aparecerem as competições organizadas, elas embrenham-se em estranhos desafios, por exemplo, fixando por mais tempo o sol, resistindo às cócegas, não pestanejando, deixando de respirar, em que os adversários procuram provar a sua capacidade de resistência (Caillois, 1990). Já quando a criança se serve das brincadeiras de competição ou de roda, em que decide participar, cria um distanciamento voluntário do mundo ambiente e entra num mundo em que ela tem poder, onde pode criar, em que as regras do jogo assumem um valor diferente do que têm no mundo dos adultos. No jogo ela evade-se do real e cresce, tentando realizar-se no seu mundo lúdico, onde pode ser tudo o que quer ser. 0 jogo apresenta, assim, todas as caraterísticas lúdicas: ordem, tensão, movimento, mudança, solenidade, ritmo e entusiasmo. Por isso, brincar é o trabalho da criança e é por meio das suas conquistas no jogo que ela se afirma, proclama o seu poder, explora, compreende e assimila gradualmente as regras e os padrões do mundo, absorvendo-o em doses bem à sua medida. Na sua essência, todas as formas de jogos são tentativas de assimilar experiências pelo organismo humano. 
Até cerca do ano e meio de idade, o jogo é apenas uma série de exercícios motores, mas, por volta dos dois anos, o jogo torna-se simbólico (Piaget, 1977). A partir desta idade, devido ao desabrochar do pensamento simbólico, a criança tem meios de se evadir do real, de dar livre curso à sua necessidade de domínio, sem entrar em constante luta com o meio: podemos acompanhar o itinerário do Ego que se afirma pelas jogos, das intermináveis histórias que conta a si mesma e dos produtos da fantasia. A partir dos sete anos de idade surgem jogos com um caráter novo, os jogos sociais: entre os rapazes, os jogos mais em voga são os jogos de proeza que, quando atingem uma organização rudimentar, tornam-se jogos de competição e são o anúncio dos desportos individuais (Chateau, 1975). Nas raparigas, os jogos de proeza têm menos importância, porque elas têm mais facilidade em se organizarem, mas, em contrapartida, os jogos de imitação coletiva e alguns jogos tradicionais ocupam também, entre elas, um lugar de importância. A partir dos dez anos desenvolvem-se, então, os jogos de grupo organizado, os jogos tradicionais, que decorrem dos jogos de proeza.

O jogo é um fenómeno social na medida em que a atividade lúdica surge como uma reprodução e uma representação das relações sociais. Contudo, as leis e os costumes da vida diária são reestruturados segundo uma lógica que, muitas vezes, não faz sentido na dimensão do quotidiano. Os jogos tomam de empréstimo ações e significados das práticas do dia-a-dia, mas,

ao contrário do que frequentemente se afirma, o jogo não é aprendizagem para o trabalho. Só aparentemente antecipa as actividades do adulto. [...] O jogo não prepara para uma profissão definida; introduz o indivíduo na vida, no seu todo, aumentando-lhe as capacidades para ultrapassar os obstáculos ou para fazer face às dificuldades. (Caillois, 1990, p. 16)

Também os brinquedos têm uma função social, como exteriorização de certo nível de cultura e de vida (Bandet; Sarazanas, 1975).

Associados aos jogos temos os brinquedos, objetos culturais destinados aos jogos infantis. A tradição dos brinquedos feitos pela própria criança ou por familiares e amigos para diversão da criança, os chamados brinquedos populares, observa-se em todos os lugares e tempos (Amado, 2002). A produção do brinquedo tornava-se, em si mesma, uma brincadeira ou um jogo para a criança que o fazia, com diversas consequências no plano do desenvolvimento físico, psicológico, social e cultural.

Os brinquedos, ao serem detentores de uma coerência expressiva, no intuito de divertir, são considerados objetos iniciáticos ao código da sociedade, sendo instrumentos de inserção social, possuem ordens dissimuladas e padrões comportamentais (Teixeira, Barroco, 1987). Assim, os brinquedos não são objectos insignificantes nem fúteis, antes pelo contrário, eles são "instrumentos insubstituíveis do desenvolvimento da criança" (Bandet; Sarazanas, 1975, p. 149). O brinquedo não é mais do que um acessório que por si mesmo se torna elemento suficiente para o jogo. $\mathrm{O}$ brinquedo incita à atividade lúdica $\mathrm{e}$ é a utilização do objeto que lhe confere o caráter de brinquedo. Desde os tempos mais remotos que a criança brincou com a areia e, já na Antiguidade, a criança dispunha de todo um leque de brinquedos que Ihe faziam companhia durante o crescimento (Manson, 2002). Segundo Jeanne Bandet e Réjane Sarazanas, "os brinquedos que perduram 
através dos séculos correspondem a necessidades imutáveis no homem; são reveladoras de funções psicológicas constantes: os guizos, as bonecas, as armas, os animais foram e serão sempre os companheiros queridos das crianças" (1975, p. 35).

Segundo Michel Manson (2002), o ioiô já era utilizado na Antiguidade egípcia e grega, antes da sua fabricação industrial na terceira década do século 20. Os brinquedos mais vulgares, nas primeiras décadas do século vinte, eram as andas, as fundas, as fisgas, os moinhos, as casinhas e os pombais; a bola também era, naturalmente, um brinquedo vulgar feito de papel velho ou de jornal, trapos, meias velhas; o iô-iô era o brinquedo da moda nos anos vinte (Lavado, 2004).

O pião, por exemplo, era um brinquedo que servia de suporte a provas de perícia individual, enquanto que a bola necessitava de um coletivo de jogadores. De acordo com Madalena Braz Teixeira e Carlos Barroco (1987), o pião é dos brinquedos com maior constância cultural. Para o jogo do pião é necessário também um baraço, com que se envolve o pião a partir do bico, cuja ponta superior fica solta de modo a envolver o polegar e o dedo médio do jogador. Este jogo pode ser efectuado por um jogador isolado, ou por dois ou mais que se desafiam entre si na tentativa de atingirem e partirem o pião do adversário (Hasse; Amado, 1992).

Se incorporarmos nesta lista de brinquedos as bonecas é curioso verificar que "os brinquedos das raparigas destinam-se a imitar condutas próximas, realistas, domésticas, enquanto os dos rapazes apelam para actividades distantes, romanescas, inacessíveis ou até francamente irreais" (Caillois, 1990, p. 41). A atividade lúdica que envolvia o uso das bonecas correspondia a uma iniciação das meninas no mundo doméstico, tradicionalmente feminino, pois, com esses objetos se reproduz toda uma panóplia de gestos, papéis e atitudes do quotidiano, que contribuem para a socialização da criança no mundo dos adultos. Os materiais postos à disposição pela indústria são utilizados pelas crianças no fabrico das suas bonecas, sendo essencialmente usados tecidos e fios de materiais têxteis. Os trapos ou farrapos eram o material preferido pelas raparigas para fazerem as suas bonecas (Amado, 2002). Com esses materiais, que resultavam muitas vezes de desperdícios de consumo, as crianças construíam as bonecas com as quais simulavam os rituais da vida, como o comer, o dormir, o casar, o baptizar ou mesmo o morrer. Estes rituais surgem frequentemente repetidos de uma forma simbólica nas brincadeiras das crianças.

A boneca, sendo um elemento antiquíssimo e eterno da atividade lúdica, é também considerada o símbolo do brinquedo (Teixeira; Barroco, 1987). A boneca é, por excelência, o brinquedo onde se cristalizam os desejos e afectos infantis; sendo uma representação humana, é frequentemente provida de membros articulados, de forma a melhor imitar a vida, possibilitando o desempenho de todos os papéis e a prática de todos os desaires simbólicos e imaginários. O conteúdo sexual assumido pela boneca mantevese ao longo dos séculos: "Velada, sofisticada ou despudoramente, a boneca - mulher sexo é uma constante do inconsciente colectivo e representa os mitos da virgem, da mãe e da prostituta" (Teixeira; Barroco, 1987). As bonecas mais antigas de que se tem conhecimento remontam à Mesopotâmia e ao Egipto e foram encontradas em escavações arquológicas juntamente com outros brinquedos. De salientar que, na Idade Média, a boneca foi usada também para outro fim que não o de brinquedo, pois era utilizada numa dimensão para-religiosa em práticas de bruxaria e feitiçaria. 
O processo de transmissão do lúdico garante a perpetuação dos gestos, das sonoridades e dos aspectos ritualizados do grupo e da comunidade envolvidos, pelo que, tudo aponta para que a atividade lúdica das crianças pertencentes às classes sociais mais desfavorecidas, especialmente as do sexo masculino, estivesse próxima do lúdico dos adultos. Ora, o lúdico dos homens da classe trabalhadora girava em volta de jogos que se faziam nas traseiras das tabernas, como relata, num dos seus livros de memórias, João Liberal: "Aí pelos anos 20-40, as tabernas proliferavam por tudo quanto era rua e sítio. [...] A taberna do Pau Louro possuía um enorme quintal, tal como outras, aproveitado para os clientes se distraírem a jogar a laranjinha e a malha" (Liberal, 1999, p. 130) ${ }^{3}$. Como eram jogos que juntavam, normalmente, um razoável número de assistentes, é natural que houvesse alguns rapazes entre a assistência. Segundo o barreirense João Liberal, nascido em fevereiro de 1922, o entretenimento dos rapazes consistia em jogos tradicionais, nomeadamente o da bola, o do berlinde, o do pião, o de saltar às uvas, correr com o arco e gancheta, entre outros, enquanto que as rapariguinhas entregavam-se, principalmente a jogar à cabra-cega, à semana, às escondidas, participando igualmente em rodas, cantando e dançando animadamente (Liberal, 1999, p. 138).

A ação da criança centra-se na atividade lúdica, sendo esta vital para o seu desenvolvimento, quer a nível corporal, da inteligência, das emoções e mesmo da própria afetividade. A atividade lúdica infantil é indissociável da cultura de um povo, dado ser ela própria um conjunto de práticas antiquíssimas que traduzem e transmitem uma identidade cultural. É também uma forma de produção social e de aprendizagem. Tal como a própria vida, os jogos praticados pelas crianças pressupõem regras às quais têm de se submeter sob pena de serem excluídas.

Todo o jogo tem as suas regras que determinam o que deve ser cumprido dentro do espaço e do tempo traçados pelo jogo, criando a ordem dentro desses limites (Huizinga, 1951). Jogar coletivamente significa construir e respeitar regras que delimitam o próprio jogo, compartilhar com os outros jogadores o mesmo repertório cultural inspirador temático do jogo, partilhar afinidades no criar e recriar com base nesse mesmo repertório. As regras são intrínsecas à busca do prazer e consistem em tornar viável o fim proposto da ação pela correta utilização de meios.

Segundo Jean Piaget (1999), antes dos seis ou sete anos, os miúdos quando jogam ao berlinde, por exemplo, ajustam as regras cada um à sua maneira e crêem mesmo poder ganhar todos ao mesmo tempo, por não se preocuparem com o cariz normativo deste jogo social. Nessa fase eles jogam em comum, apesar de não cooperarem verdadeiramente, pois cada um interpreta à sua maneira as normas procedentes dos mais velhos, mas quando lhes é solicitada a invenção de novas regras eles resistem a toda a mudança dos modelos sagrados transmitidos pelos mais velhos. Só a partir dos dez anos

\footnotetext{
${ }^{3}$ Este autor descreve assim os jogos citados: "a laranjinha consistia num jogo formado por vários pinos de madeira, em forma aproximada de garrrafa, dispostos, ao lado uns dos outros, no fundo do quintal, todo ele cimentado ou de chão térreo duro batido, a uns poucos metros do local de arremesso (não prevejo a distância exacta). Os intervenientes atiravam uma bola (a laranjinha) de ferro ou massa, que rolava, rasteira ao chão, contra os pinos. Ao fim de umas tantas jogadas, vencia quem mais pinos derrubasse. $O$ jogo da malha (uma chapa circular metálica, bastante pesada), praticado em chão térreo batido, baseavase na tentativa de derrubar um único pino, e quem o derrubasse também mais vezes seria naturalmente o vencedor" (Liberal, 1999, p. 131). 
é que aceitam as inovações, mas só se submetem a uma nova regra se esta for adoptada pela maioria do grupo. Na faixa intermédia entre os seis e os nove anos, a regra tradicional do jogo, aprendida com os mais velhos, é respeitada.

O jogo do berlinde é um jogo complexo efetuado, em particular, pelos rapazes entre os sete e os doze anos de idade. Existem várias maneiras de o jogar e vários tipos de berlindes com dimensões, peso, cores, texturas, valores e significados distintos entre si de acordo com o jogo em que são usados (Hasse; Amado, 1992). Algumas das variantes do jogo do berlinde já eram conhecidas entre os egipcíos, gregos e romanos, "sendo considerado como reminiscência de práticas divinatórias" (Amado, 2002, p. 162). O jogo consiste em projetar os berlindes por meio de um deles, que se segura entre o polegar e o indicador, e que é lançado sobre um dos outros por um pequeno toque rápido do dedo médio que o impulsiona para diante. Ao longo do jogo, conquistam-se e perdem-se posições, ganham-se e perdem-se berlindes, saindo vencedor aquele que conseguir acumular as melhores posições e o maior número de berlindes, ou seja, o que conseguir efectuar as melhores jogadas.

Os jogos e as brincadeiras constituem elementos aglutinadores, dado que são processos de aproximação e de reunião de qualquer grupo. Nas sociedades tradicionais, o jogo aproxima-se da festa, na medida em que é público e coletivo, mesmo quando se reduz a dois elementos jogadores, existe um público à volta que, de certa forma, também participa do jogo, dando um carácter aglomerante a este. Também nas crianças a reunião de amigos é um aspecto importante do jogo, ao tratar-se de uma atividade que sugere contacto, ligação com o outro, com o mundo e consigo mesmo. Todo o jogo tem uma vocação social, pois, "por mais individual que se suponha ser o manusear do brinquedo com que se joga: papagaio, ioiô, pião, diabolo, passavolante ou arco, deixaríamos rapidamente de nos divertir, se acaso não houvesse nem concorrentes nem espectadores, por imaginários que fossem" (Caillois, 1990, p. 59).

\section{Os jogos dentro da aula}

É por todos reconhecido a importância que o jogo tem na formação e no desenvolvimento do ser humano. Para além da importância que tem na vida da criança, do prazer sensorial e de certa forma estético que lhe é próprio, o jogo constitui uma base e um fator de cultura (Huizinga, 1951).

O jogo constitui um fenómeno de vital importância para o equilíbrio do ser social, cultural e psíquico, pelo que pode ser aproveitado, dentro de uma prática de educação, pelas suas funções culturais e catárticas. Jean Chateau (1975) dizia que o jogo deu origem a muitas atividades superiores, senão mesmo a todas elas, desde a arte, a ciência, o trabalho, entre outras, pelo que se procura utilizá-lo como meio de educação.

Claparède (1931) preconizava que se poderia estabelecer a ponte entre a escola e a vida utilizando o jogo, por uma concepção funcional da educação. Leite de Vasconcellos (1933) prescrevia a etnografia como auxiliar da pedagogia infantil, porque, quando vão para a escola, as crianças levam já consigo "copioso peculio tradicional, que obtiveram das mães e do contacto com o povo", pelo que "fará excelente obra o mestre-escola que seleccione esse peculio, o regule e complete, aplicando-o ao desenvolvimento psiquico e fisico dos seus alunos, que ao mesmo tempo aí encontrarão grande prazer" (Vasconcellos, 1933, p. 335). Segundo ele, as adivinhas contribuíam para despertar a 
atenção, a recitação de cantigas promovia o gosto literário, a aprendizagem de romances e contos abria a memória e ativava a imaginação, os provérbios acalentavam o senso moral, e os jogos, "como o da bola e o da barra, o antigo, bem preferiveis a alguns que nos chegaram recentemente de Inglaterra", fortaleciam os músculos e desenvolviam a destreza (Vasconcellos, 1933, p. 336).

Também o inspetor sanitário Costa Sacadura (1906) prescrevia que os jogos que poderiam ser adoptados nas escolas enquadrados nos exercícios físicos seriam, entre outros, o jogo do pião, a bilharda, a barra, o caçador, o pilha-três, os cantinhos, a bola, todos estes para os rapazes, e o jogo da pela ${ }^{4}$ para as raparigas. Segundo ele,

entre os exercicios physicos que não exigem preparação, ha os jogos mais usuaes de cada região, que podem ser introduzidos na escola, debaixo da vigilancia do professor intelligente e carinhoso; e nas horas de recreio as creanças executá-los-hão com alegria, actuando não só na sua força muscular, mas tambem no seu desenvolvimento intellectual. (Sacadura, 1906, p. 328)

O recurso ao jogo para fins educativos não é uma ideia recente, pois, já Platão na sua obra República recomendava: "Fazei de maneira que as crianças se instruam jogando; tereis assim ocasião de conhecer as disposições de cada uma" (apud Planchard, 1979 , p. 214). Contudo, só nos séculos 19 e 20 é que o jogo é valorizado como um instrumento educativo e didático. Por exemplo, António Sérgio, numa conferência educativa proferida no Barreiro, em dezembro de 1924, sobre o que deveria ser o ensino primário, "expôs uma das muitas fórmulas do processo analítico de ensinar a ler - os jogos instructivos, interessantes distracções para as crianças, que as ensinam a fixar palavras sem esforço de memória maçador; uns jogos para os papás ensinarem, ao serão os seus filhinhos a ler, distraindo-os e distraindo-se (Éco do Barreiro, $1^{\circ}$ jan., 1925).

Por seu turno, Freinet (1874) entendia a utilização do jogo na escola na perspetiva de jogo-trabalho, ou seja, ele preconizava a realização de atividades lúdicas, mas que tivessem procedência nas mesmas necessidades e tendências que justificam o trabalho adulto. Numa passagem no livro $A$ educação pelo trabalho explicava que o jogo-trabalho da criança era aparentado à atividade calma do homem sem preocupações económicas. Nesta base,

a preocupação educativa essencial deve ser realizar na família se possível, pelo menos na escola e à volta da escola, um mundo que esteja verdadeiramente à medida da criança, evoluindo ao seu ritmo, respondendo às suas necessidades, e no qual ela poderá entregar-se aos trabalhos-jogos que são susceptíveis de corresponder às aspirações naturais e funcionais do seu ser. (Freinet, 1974, p. 101)

\footnotetext{
${ }^{4}$ De acordo com a informação contida no livro Jogos e Brinquedos Tradicionais, de Manuela Hasse e João da Silva Amado (1992), o jogo da péla era um jogo de arremesso de uma bola de pequenas dimensões, muito antigo, e, segundo consta, alguns tipos de pélas foram inclusive utilizados, no passado, como forma de transportar recados de amor entre os namorados. A partir dos finais do século XVIII este jogo foi sofrendo algumas transformações até chegar à modalidade desportiva conhecida hoje como ténis, embora também permanecesse na sua maneira de jogar simples.
} 
Segundo o pedagogo Émile Planchard (1982), querer coartar a atividade lúdica nas crianças, sob o argumento de que ela representa uma perda inútil de energia, é erguer resistência ao seu desenvolvimento e ao enriquecimento da sua experiência, mas "utilizar o jogo, adaptando as suas formas exteriores a finalidades educativas precisas, é canalizar uma das mais profundas energias da infância" (p. 262). Em certa medida podemos considerar que é dentro desta mesma linha de pensamento que Jeanne Bandet e Réjane Sarazanas afirmam que "a criança aprenderá, pouco a pouco, a transferir para o trabalho, se este corresponder às suas necessidades e aos seus gostos, o desejo de acção e a alegria do êxito que já tinha descoberto ao brincar" (Bandet, Sarazanas, 1975, p. 153).

De acordo com Planchard (1979), o princípio aplicado nos jogos educativos e didáticos é o da transferência de energia, ou seja, "a um interesse que não pode ter ainda senão uma acção mínima ou nula sobre o comportamento da criança, substitui-se um interesse imediato e poderoso" (p. 215) e como "em todas as crianças, os interesses afastados e superiores são ainda inoperantes por si próprios" é necessário "substituir-lhes ou, melhor, sobrepor-lhes interesses imediatos e concretos" (p. 513). Desta forma, o jogo serviu de mote inspirador a diversos métodos de educação e à criação de materiais didáticos, como é o caso, por exemplo, dos jogos de Froebel, Montessori e Decroly, baseados na educação sensorial e da linguagem, da atividade motora e do aperfeiçoamento da lógica infantil.

\section{Locais por excelência para as brincadeiras}

Começando pelo caminho para a escola, espaço informal que separa a casa da escola, constata-se que ele é preenchido por interações entre as crianças, que se organizam ao sabor do parentesco, da amizade e das relações vicinais:

No caminho para a escola, a interacção entre os géneros diverge muito, mesmo no caso do Lavradio. Isto porque há raparigas que têm irmãos rapazes e brincam com eles ainda que sejam da mesma idade - embora tenham grupos de brincadeira diferentes, pontualmente juntam-se, ou juntam-se com primos ou com vizinhos - noutros casos, há um afastamento total e completo, ou que assim se apresenta no discurso dos informantes, entre rapazes e raparigas. (Lavado, 2004, p. 9)

$\mathrm{Na}$ escola o recreio é o local por excelência destinado aos jogos e às brincadeiras e o tempo a eles destinado é o do intervalo das aulas, dado que "o jogo é essencialmente uma ocupação separada, cuidadosamente isolada do resto da existência, e realizada, em geral dentro de limites precisos de tempo e de lugar" (Caillois, 1990, p. 26). O tempo do jogo começa e acaba quando se dá um sinal, remetendo assim o domínio do jogo para um universo reservado, fechado e protegido. No caso de não haver recursos a criança inventa o seu próprio cantinho num espaço oferecido ou negociado entre os pares, que acaba por ser seu, onde cria o seu campo de ação, de ilusão e de escape. Mas como podem brincar as crianças se as escolas não lhes proporcionarem espaços para esse efeito?

No caso do Barreiro, em março de 1915, o diretor da escola Conde de Ferreira, para o sexo masculino, lembrava à Câmara Municipal, por meio de ofício, da "necessidade de alargar o recinto destinado ao recreio dos seus alunos" (Livro de actas, 31 mar. 1915). Volta-se a ter o recreio como espaço reclamado no início de 1923, quando o diretor 
daquela mesma escola solicitou à Câmara Municipal que fosse feito um recreio coberto devidamente calcetado para livrar as crianças de um calor excessivo e das chuvas (Livro de actas, 7 fev. 1923). Na falta de um recreio amplo, os alunos resolviam o problema indo brincar para a praia que ficava contígua à escola: "Em muitas ocasiões, o nosso recreio era feito na praia, à solta, na brincadeira, o que originava que alguns alunos mais distraídos chegassem atrasados ao recomeço das aulas" (Liberal, 1985, p. 111). Ora, quando se frequentava uma escola que tem as traseiras voltadas para a praia e o ar que se respirava nas aulas tinha o cheiro da maresia e o som da voz dos pescadores, a atenção dispersava-se. Estas distrações tinham como consequência a reprimenda do professor: "O António não entra, pode ir para casa, e ser-lhe-á marcada falta. Quanto ao José, venha cá, que vai levar três reguadas” (Liberal, 1985, p. 111).

Mas a falta de equipamentos das escolas em nível de espaços lúdicos era a norma em Portugal. Já em 1912, Pedro José Ferreira, no discurso proferido por ocasião do Terceiro Congresso Pedagógico, salientava as más condições das nossas escolas nessa matéria e as consequências nefastas que daí advinham: "Uma escola sem um pequeno jardim, sem um gimnásio adequado, sem um terreiro para jogos e recreios, tornar-se há para as infelizes crianças, em vez de escola, um meio deformante" (Ferreira, 1913, p. 161). Outro exemplo é-nos dado por Armando Pereira que, em 1913, relativamente a espaços de recreio nas escolas, dizia na sua tese:

Alguns dos edifícios construídos expressamente para escolas, não têm recreios, nem espaço para actualmente se remediar essa falta; outros, porêm, apesar de possuirem recinto suficiente para os alunos o ocuparem nas horas de descanso, como tais terrenos são cultivados em proveito dos professores, é-lhes vedada essa faculdade. (Pereira, 1913, p. 35)

E, mais adiante, acrescentava: "Isto no que se refere a recreios ao ar livre, porque salões de recreio para os dias de chuva, em vista da falta quase geral de locais apropriados para isso, limitavam-se as crianças a permanecer nas salas de aula, nas horas de descanso, ou a vaguear aos encontrões pelos corredores" (Pereira, 1913, p. 36).

De facto, os recreios apesar de terem sido espaços menorizados nos quotidianos escolares e poucas atenções terem recebido por parte das entidades responsáveis pelo equipamento das escolas, foram povoados, ao longo dos tempos, por risos e gargalhadas, misturados com choros e desilusões, emoções próprias de quem experienciava esses espaços em jogos e brincadeiras.

\section{Notas finais}

Num tempo em que o poder da máquina se impunha no meio circundante, a atividade lúdica tendia a ficar confinada a tempos e espaços que ficavam fora do âmbito do trabalho. Na sociedade industrializada, o jogo - ao estar desligado de interesses materiais - perdeu terreno e transformou-se, gradativamente, enquanto a sociedade se tornava cada vez mais incutida pelo valor do trabalho e menos lúdica (Serra, 2004). No entanto, o jogo, no contexto escolar, podia ser um fator importante para o rompimento da dualidade entre ensino-trabalho e recreio-jogo. 
A ação da criança centra-se essencialmente na atividade lúdica, sendo esta vital para o seu desenvolvimento, quer a nível corporal, da inteligência, das emoções e mesmo da própria afetividade. A atividade lúdica infantil é indissociável da cultura de um povo, dado ser ela própria um conjunto de práticas antiquíssimas que traduzem e transmitem uma identidade cultural. É também uma forma de produção social e de aprendizagem. Tal como a própria vida, os jogos praticados pelas crianças pressupõem regras às quais têm de se submeter sob pena de serem excluídas. Associados aos jogos infantis estão os brinquedos, objetos culturais que são considerados iniciáticos ao código da sociedade e, sendo instrumentos de inserção social, possuem ordens dissimuladas e padrões comportamentais. Na génese do pensamento, da descoberta de si mesmo, da possibilidade de experimentar, de criar e de transformar, encontra-se o jogo, pelo que as brincadeiras são o meio que a criança usa para contactar com o mundo.

A tentativa de compreender o papel do jogo e do brinquedo na formação dos sujeitos tem sido tema de diversas discussões em várias áreas do conhecimento. Independentemente da época, da cultura e da classe social, os jogos e os brinquedos compõem uma parte substancial da vida da criança, pois, elas vivem mais próximas do mundo da fantasia, do encantamento, da alegria, onde a realidade e o faz-de-conta se entrecruzam e confundem.

Por tudo isto que aqui ficou dito, poder-se-á concluir que as brincadeiras vividas no recreio da escola e nos espaços que separavam a escola da casa, não seriam diferentes das brincadeiras praticadas na rua, nos páteos térreos das casas ou em qualquer outro lugar livre onde fosse possível ser-se apenas criança.

\section{Referências}

AMADO, João. Universo dos brinquedos populares. Coimbra: Quarteto, 2002.

ARQUIVO MUNICIPAL DO BARREIRO. Livro de actas das sessões da Comissão Executiva da Câmara Municipal do Barreiro. 1921-1923.

ARQUIVO MUNICIPAL DO BARREIRO. Livro de actas das sessões da Comissão Executiva da Câmara Municipal - 2 de Janeiro de 1914 a 25 de novembro de 1915.

BANDET, Jeanne \& SARAZANAS, Réjane. A criança e os brinquedos. Lisboa: Estampa, 1975.

BROUGÈRE, Gilles. A criança e a cultura lúdica. Revista da Faculdade de Educação, São Paulo, v. 24, n. 2, 1998, p. 103-116.

CAILLOIS, Roger. Os jogos e os homens: a máscara e a vertigem. Lisboa: Cotovia, 1990. CERTEAU, Michel de. A invenção do cotidiano: 1 - artes de fazer. Petrópolis: Vozes, 2003.

CHATEAU, Jean. A criança e o jogo. Coimbra: Atlântida, 1975.

CLAPARÈDE. L'éducation fonctionnelle. Neuchatel et Paris: Delachaux \& Niestlé, 1931.

ECM. Entrevista concedida a Maria Manuela Rodrigues. Barreiro, 19 set. 2002.

ÉCO DO BARREIRO. Quinzenário independente, defensor dos interesses do Barreiro. Barreiro, ano 2, n. 28, $1^{\circ}$ jan. 1925. 
FERREIRA, Pedro José. Educação física, a gimnástica e os jogos ao ar livre: quando e como devem ser ministrados. LIGA NACIONAL DE INSTRUÇÃO, TERCEIRO CONGRESSO PEDAGÓGICO - ABRIL DE 1912. Lisboa: Imprensa Nacional, 1913, p. 157-164.

FINK, Eugene. Le jeu comme symbole du monde. Paris: Minuit, 1966.

FREINET, Celestin. A educação pelo trabalho. Volume I. Lisboa: Presença, 1974.

HASSE, Manuela; AMADO, João da Silva. Jogos e brinquedos tradicionais. Lisboa: Instituto de Apoio à Criança, 1992.

HUIZINGA, Johan. Homo ludens: essai sur la fonction sociale du jeu. Paris: Gallimard, 1951.

JBT. Entrevista concedida a Maria Manuela Rodrigues. Barreiro, 21 fev. 2003.

LAVADO, Ana Felisbela de Albuquerque Piedade Pires. No trilho dos pequenos deuses: aprendizagem da memória. Lisboa: UNL, 2004, 382f. Tese (doutorado em Antropologia Social e Cultural). Faculdade de Ciências Sociais e Humanas, Universidade Nova de Lisboa.

LIBERAL, João. Histórias breves de antigamente. Barreiro: Autor, 1999.

LIBERAL, João. Quadros-memórias da minha infância. Barreiro: Autor, 1985.

MANSON, Michel. História do brinquedo e dos jogos: brincar através dos tempos. Lisboa: Teorema, 2002.

PEREIRA, Armando dos Santos Pinto. A higiene nas escolas primárias do Porto. Porto: Empresa Gráfica A Universal, 1913. Dissertação inaugural apresentada à Faculdade de Medicina do Porto.

PEREIRA, Sara Marques (coord.). Memórias da escola primária. Lisboa: Livros Horizonte, 2002.

PIAGET, Jean. Pedagogia. Lisboa: Instituto Piaget, 1999.

PIAGET, Jean. Problemas de psicologia genética. Lisboa: Dom Quixote, 1977.

PLANCHARD, Émile. A pedagogia contemporânea. Coimbra: Coimbra, 1982.

PLANCHARD, Émile. Introdução à pedagogia. Coimbra: Coimbra, 1979.

SACADURA, Costa Sacadura. Educação physica. In Boletim da Direcção Geral da Instrucção Publica, Ano IV. Julho-Dezembro de 1905. Fascículo VII-XII. Lisboa: Imprensa Nacional, 1906, p. 323-330.

SERRA, Mário Cameira. O jogo e o trabalho: episódios lúdico-festivos das antigas ocupações agrícolas e pastoris colectivas. Lisboa: Colibri/Inatel, 2004.

TEIXEIRA, Madalena Braz; BARROCO, Carlos. O brinquedo português. Lisboa: Bertrand, 1987.

VASCONCELLOS, J. Leite de. Etnografia portuguesa. Volume I. Lisboa: Imprensa Nacional de Lisboa, 1933. 
MARIA MANUELA PEREIRA FIGUEIREDO RODRIGUES é doutora em Ciências da Educação pela Universidade Nova de Lisboa. Investigadora do Instituto de Educação da Universidade de Lisboa, Unidade de Investigação e Desenvolvimento em Educação e Formação, grupo de investigação da História da Educação.

Endereço: Rua do Bom Sucesso, 20 - 2835-327 - Lavradio - Portugal.

E-mail: mmpfrodrigues@hotmail.com.

Recebido em 16 de novembro de 2014.

Aceito em 5 de junho de 2015. 